\title{
Comparative study of ormeloxifene and low dose oral contraceptive pill for the treatment of dysfunctional uterine bleeding in peri-menopausal age group
}

\author{
Maitri Shah, Chirayu Parmar, Riddhi Gor*
}

Department of Obstetrics and Gynecology, Baroda Medical College, Vadodara, Gujarat, India

Received: 16 June 2021

Accepted: 12 July 2021

\author{
*Correspondence: \\ Dr. Riddhi Gor, \\ E-mail: ridz.rdg@gmail.com
}

Copyright: (C) the author(s), publisher and licensee Medip Academy. This is an open-access article distributed under the terms of the Creative Commons Attribution Non-Commercial License, which permits unrestricted non-commercial use, distribution, and reproduction in any medium, provided the original work is properly cited.

\begin{abstract}
Background: Dysfunctional uterine bleeding (DUB) is the most common menstrual disorder of women in any age group and is a diagnosis of exclusion. Medical management of menorrhagia is a difficult task as there are wide variations in the available drugs and a lot of different regimes are available. Present study evaluates efficacy and safety of ormeloxifene a selective estrogen receptor modulator (SERMs) as compared to combined oral contraceptive pills in treatment of dysfunctional uterine bleeding in perimenopausal women.

Methods: Total 60 patients meeting with our inclusion and exclusion criteria were enrolled in the study over a time period of 6 months and were further divided randomly into two groups. One group was given Ormeloxifene and the other group was treated with combined oral contraceptive pills (COCP) over a period of six months. The outcome variables noted were pictorial blood loss assessment chart (PBAC) score, Hb level and combined endometrial thickness (CET). Quantitative variables were compared using independent t test/Mann-Whitney test between the two groups and paired $t$ Test/Wilcoxon test was used for comparison between pre and post within the group.

Results: Both ormeloxifene and COCP significantly reduce blood loss in these patients evidenced by decrease of PBAC score, rise in hemoglobin levels and decrease in CET levels. However, ormeloxifene was found to be superior to COCP in reducing the menstrual blood loss. Ormeloxifene was also tolerated better compared to COCP with fewer side effects experienced by patients.
\end{abstract}

Keywords: Ormeloxifene, Perimenopausal, DUB

\section{INTRODUCTION}

Dysfunctional uterine bleeding (DUB) is defined as abnormal uterine bleeding without any clinically detectable organic, systemic and iatrogenic cause. It is the most common menstrual disorder of women in any age group and is a diagnosis of exclusion. It can affect any woman from menarche to menopause, but is more common in extreme age group. ${ }^{1,2}$

The impact of DUB is of immense importance to society and economy. It causes morbidity, anemia and unnecessary hysterectomies in perimenopausal women. It affects $10-30 \%$ of women at some stage in their life. The prevalence of menorrhagia (menstrual blood loss $>80 \mathrm{ml}$ per cycle) is almost one third in population of United States. Unfortunately, there are no published reports from developing Asian countries. ${ }^{3}$

Dysfunctional uterine bleeding may be ovulatory or anovulatory. In most cases of DUB, bleeding results from abnormal function of hypothalamo-pituitary-ovarian axis leading to anovulatory cycles. So, progesterone is not produced to stabilize cyclic withdrawal of estrogenprepared endometrium leading to amenorrhea, metrorrhagia and menorrhagia. In small portion of women 
with DUB, ovulation occurs regularly. Though the predominant cause of DUB is prolonged estrogenic stimulation on the endometrium, recently attention has been focused on local endometrial factors such as imbalance of different components of endometrial prostaglandins, endometrial vasculopathy or local coagulopathy. Defects of local endometrial receptors either estrogen or progesterone can cause an abnormal endometrial response to normal hormonal milieu.

In India, low socioeconomic status, poverty and repeated child birth make all women vulnerable to develop severe anemia even with moderate blood loss. This often necessitates blood transfusions. Unavailability of adequate health care and diagnostic aids in rural areas often delay the appropriate management of these patients.

Traditionally surgical treatment only treats the symptoms rather pathology. Globally health care systems are focusing on low morbidity and low-cost therapeutic interventions. Thus, more and more women are looking forward to an effective non-surgical therapy. ${ }^{4}$

Hence, medical management for DUB is high on priority list. Medical management of menorrhagia is a difficult task and wide variations in the available drugs prescribed and tedious regimes for this condition show a lack of consensus for medical treatment. ${ }^{5}$ The medical options for initial management of DUB include anti-fibrinolytics (tranexamic acid) and ethamsylate, non-steroidal antiinflammatory drugs (NSAIDs), combined estrogen and progesterone or progesterone alone, high dose estrogens, gonadotropin-releasing hormone agonists, danazol and levonorgesterol releasing intrauterine systems. ${ }^{6}$ Danazol, progesterone and gonadotropin-releasing hormone analogues are all effective in terms of reducing menstrual blood loss but adverse effects and costs limit their long term use.

SERMs popularly has known as designer estrogen/fantasy estrogen because they selectively bind with high affinity to estrogen receptors and act as estrogen agonists in some tissues and estrogen antagonists in others. ${ }^{7,8}$ Ormeloxifene, a third generation SERM, antagonizes the effect of estrogen on uterine and breast tissue and stimulates its effect on vagina, bone, cardiovascular and central nervous system. $^{9}$ It is a non-steroidal, non hormonal oral contraceptive, which is available as a birth control pill since early 1990s. It is especially beneficial in perimenopausal women as it has no uterine stimulation, prevents bone loss, does not increase the risk of breast cancer, lowers cholesterol level and maintains cognitive function of the brain. ${ }^{10}$ It has the additional advantage of reducing premenstrual symptoms, mastalgia and dysmenorrhea. Unlike progesterone, ormeloxifene does not produce spotting, breakthrough bleeding or menorrhagia. ${ }^{11}$ The effect of this SERM on the vascular endothelium leads to decrease in blood loss and thereby amelioration of symptoms in dysfunctional uterine bleeding. Dose: $60 \mathrm{mg}$ orally twice a week for 12 weeks then once a week in next 12 week. Safety profile of this drug is excellent with very few side effects like nausea, vomiting, headache, weight gain, delayed or prolonged menstrual period.

Our study aims to find out efficacy and safety of ormeloxifene as compared to combined oral contraceptive pills in treatment of dysfunctional uterine bleeding in women of perimenopausal age group.

\section{METHODS}

This is a prospective randomized control trial in which women of perimenopausal age group (40-55 years) having DUB, attending the gynecology outdoor patient department of a tertiary care hospital of central India were included. Patients signing the informed consent form were evaluated for eligibility. Total 60 patients meeting with our inclusion and exclusion criteria were enrolled in the study over a time period of 6 months. These patients were further divided randomly into two groups by random numbers that were generated prior to initiation of the study using epiinfo software. So, there were 30 patients in each group.

The study protocols were approved by institutional ethics committee for human research (IECHR) of the same hospital. It was carried out from November 2017 to November 2018. All women of perimenopausal age group (40-55 years) with DUB excluding all other structural and functional causes of abnormal uterine bleeding and those willing to give informed consent were included in the study. All those women with pelvic pathologies like uterine fibroids, adenomyosis and ovarian tumors; having malignancies of uterus/cervix/ovary/vagina/endometrial hyperplasia with atypia; having medical diseases like-liver dysfunction, heart disease, migraines, stroke, renal disease, hypo/hyperthyroidism, platelet disorders or coagulopathy, previous history of thrombosis; women who have pregnancy, recent abortion, using IUCDs or oral contraceptives or those who are lactating in first 6 months of post-natal period and those having hypersensitivity to ormeloxifene were excluded from the study.

\section{Intervention}

\section{$1^{\text {st }}$ contact session}

After noting down demographic profile of all the participants, a review of medical and gynecological history was done. Detailed history of menstrual problems was taken. Patients who were on other drugs or hormonal treatment for DUB were asked to stop the drug and reassessed after one month. General examination was done to assess anemia, and to rule out any signs and symptoms of bleeding disorders, hypothyroidism and jaundice. Pelvic examination was done to rule out pelvic pathologies. Patients included had undergone transvaginal ultrasound to rule out any other uterine or extrauterine pathologies and measurement of CET. Baseline investigations were done for hemoglobin levels and complete blood count and 
platelet count, liver function tests and renal function tests. Menstrual blood loss for all patients was objectively assessed by PBAC. Women were given instructions on how to do PBAC scoring according to degree of soiling of sanitary napkins and number and size of clots passed and PBAC score of previous menstrual cycle was obtained.

PBAC scoring system

Table 1: PBAC scoring system.

\begin{tabular}{|ll|}
\hline Use of pad per day & Points to be given \\
\hline Pads lightly soiled & 1 \\
\hline Moderately soiled & 5 \\
\hline Saturated & 20 \\
\hline Clots small (<Rupee coin) & 1 \\
\hline Large (>Rupee coin) & 5 \\
\hline
\end{tabular}

Patients were counselled to use same brand of sanitary napkin throughout study to maintain uniformity. All the patients were then divided randomly into ormeloxifene group and COCP group.

Ormeloxifene group patients were given ormeloxifene tablet $60 \mathrm{mg}$ twice a week for 12 weeks followed by $60 \mathrm{mg}$ once a week for next 12 weeks. Treatment period started from the day of inclusion in study. Patients in the COCP Group were given low dose oral contraceptive pills containing $30 \mu \mathrm{g}$ of ethinyl estradiol and $150 \mu \mathrm{g}$ levonorgestrol from day one of upcoming menstrual cycle to day 21 for 6 consecutive cycles. Standard drugs of same brand were provided to patients in each group by the author himself, free of cost.

\section{$2^{\text {nd }}$ and subsequent visits}

All these subjects in both the groups were called after three and six months and were evaluated during their follow up regarding efficacy and safety of drug.

For assessing efficacy follow up was done after $3^{\text {rd }}$ and $6^{\text {th }}$ month of initiation of the treatment. After 3 months the improvement in the symptoms were assessed in the form of amount of bleeding (assessed by PBAC score). After 6 months at the end of the treatment, patients' improvement was assessed by performing blood hemoglobin levels, CET and PBAC score.

For assessing safety of the drug, any of these side effects (amenorrhea, weight gain, nausea and vomiting, headache) if present were noted in both the groups. In first and last visit, TVS was done to measure the difference in CET pre and post treatment.

In ormeloxifene group, 2 patients withdrew their consent after one or two doses of the drug, and one patient opted for hysterectomy after one month of treatment so they were excluded from the study. In COCP group, out of 30 patients, 2 were lost to follow up in the first month of study and were excluded.

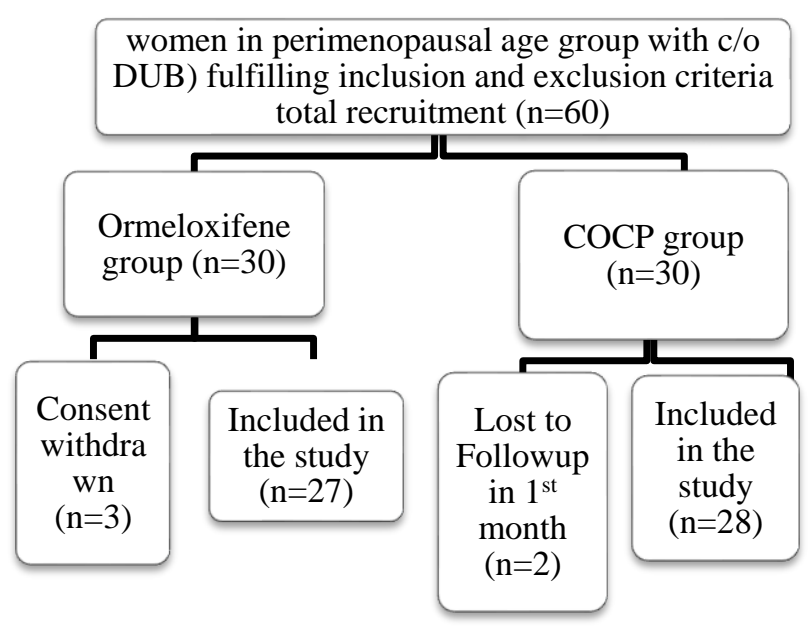

Figure 1: Flow chart of recruitment of subjects in both groups.

\section{Outcome variables}

Primary outcome was improvement in PBAC score while secondary outcomes assessed were rise in hemoglobin levels and decrease in CET. All data was entered in excel sheet with serial no. files were kept password protected.

\section{Statistical methods used}

Categorical variables were presented in number and percentage (\%) and continuous variables were presented as mean \pm SD and median. Normality of data was tested by Kolmogorov-Smirnov test. If the normality was rejected then non parametric test was used.

Statistical tests were applied as follows-1. Quantitative variables were compared using independent $t$ test/MannWhitney test (when the data sets were not normally distributed) between the two groups and paired $t$ test/Wilcoxon test was used for comparison between pre and post within the group and 2. Qualitative variables were correlated using chi-square test. A $p<0.05$ was considered statistically significant. The data was entered in MS excel spreadsheet and analysis was done using statistical package for social sciences (SPSS) version 21.0.

\section{RESULTS}

The mean age of the patients in ormeloxifene group was $45.53 \pm 3$ years and in combined oral contraceptive pills group was $45.6 \pm 2.03$ years. No significant difference in the age distribution of two groups was seen in the study $(\mathrm{p}>0.05)$ It is shown in Table 2.

In our study, in ormeloxifene group the mean PBAC score before treatment of the patients was $323.37 \pm 86.59$. The mean PBAC score pre-treatment was $325.22 \pm 89.22$. A significant decrease in the PBAC score was seen after 3 months and 6 months as compared to before treatment $(\mathrm{p}<0.05)$. It has been shown in Table 3. 
Table 2: Distribution of age in both groups.

\begin{tabular}{|c|c|c|c|c|}
\hline \multirow[b]{2}{*}{ Age (years) } & \multicolumn{2}{|l|}{ Groups } & \multirow[b]{2}{*}{ Total } & \multirow[b]{2}{*}{ P value } \\
\hline & $\begin{array}{l}\text { Ormeloxifene, } \\
(\mathbf{n}=30)(\%)\end{array}$ & $\begin{array}{l}\text { Combined oral contraceptive } \\
\text { pills, }(\mathbf{n}=\mathbf{3 0})(\%)\end{array}$ & & \\
\hline $40-44$ & $8(26.67)$ & $10(33.33)$ & $18(30)$ & \multirow{4}{*}{0.54} \\
\hline $45-49$ & $19(63.33)$ & $19(63.33)$ & $38(63.33)$ & \\
\hline $50-55$ & $3(10.00)$ & $1(3.33)$ & $4(6.67)$ & \\
\hline Total & $30(100)$ & $30(100)$ & $60(100)$ & \\
\hline Mean \pm SD & $45.53 \pm 3$ & $45.6 \pm 2.03$ & $45.57 \pm 2.54$ & \multirow{2}{*}{0.92} \\
\hline Median (IQR) & $45(44-48)$ & $45(44-48)$ & $45(44-48)$ & \\
\hline
\end{tabular}

Table 3: PBAC score before and after ormeloxifene.

\begin{tabular}{|c|c|c|c|}
\hline $\begin{array}{l}\text { PBAC score } \\
\text { (Months) }\end{array}$ & $\begin{array}{l}\text { Mean } \pm \\
\text { SD }\end{array}$ & $\begin{array}{l}\text { Median } \\
\text { (IQR) }\end{array}$ & $P$ value \\
\hline $\begin{array}{l}\text { Before } \\
\text { treatment }\end{array}$ & $\begin{array}{l}325.22 \pm \\
89.22\end{array}$ & $\begin{array}{l}312 \\
(254.50- \\
361.250)\end{array}$ & \multirow{3}{*}{$<0.0001$} \\
\hline After 3 & $\begin{array}{l}119.96 \pm \\
77.65\end{array}$ & $\begin{array}{l}124 \\
(79.50-178)\end{array}$ & \\
\hline After 6 & $\begin{array}{l}68.93 \pm \\
51.65\end{array}$ & $\begin{array}{l}80 \\
(2.75- \\
107.250)\end{array}$ & \\
\hline
\end{tabular}

The mean hemoglobin pre-treatment was $8.48 \pm 0.87 \mathrm{gm}$. A significant increase in the hemoglobin levels was seen after 6 months as compared to before treatment with mean value of $10.34 \pm 1.06 \mathrm{gm}(\mathrm{p}<0.05)$. It is shown in Table 4 .

Table 4: Hemoglobin levels before and after ormeloxifene.

\begin{tabular}{llll|}
$\begin{array}{l}\text { Hemoglobin } \\
(\text { gm \%) }\end{array}$ & $\begin{array}{l}\text { Mean } \pm \\
\text { SD }\end{array}$ & $\begin{array}{l}\text { Median } \\
\text { (IQR) }\end{array}$ & P value \\
$\begin{array}{llll}\text { Before } \\
\text { treatment }\end{array}$ & $\begin{array}{l}8.48 \pm \\
0.87\end{array}$ & $\begin{array}{l}8.4 \\
(8.025-8.950)\end{array}$ & $<0.0001$ \\
\cline { 1 - 2 } After 6 & $10.34 \pm$ & $\begin{array}{l}10.2 \\
(9.575-11.07)\end{array}$ & \\
\hline
\end{tabular}

The mean CET pre-treatment was $9.37 \pm 1.62 \mathrm{~mm}$. A significant decrease in the CET was seen after 6 months as compared to before treatment with mean value of $6.94 \pm 1.26 \mathrm{~mm}(\mathrm{p}<0.05)$. It is shown in Table 5 .

Table 5: CET ( $\mathrm{mm})$ before and after ormeloxifene.

\begin{tabular}{|llll|}
$\begin{array}{l}\text { CET }(\mathrm{mm}) \\
\text { (Months) }\end{array}$ & $\begin{array}{l}\text { Mean } \pm \\
\text { SD }\end{array}$ & $\begin{array}{l}\text { Median } \\
(\text { IQR) }\end{array}$ & P value \\
\hline $\begin{array}{l}\text { Before } \\
\text { treatment }\end{array}$ & $9.37 \pm$ & $9.5(7.800-$ & \\
\cline { 1 - 3 } After 6 & 1.62 & $10.875)$ & $<0.0001$ \\
& $6.94 \pm$ & $6.8(6.125-$ & \\
& 1.26 & $7.800)$ & \\
\hline
\end{tabular}

The mean values of PBAC score before treatment in the two groups were comparable but after 6 months of treatment, mean value of PBAC score in ormeloxifene group was $68.93 \pm 51.65$ which was significantly lower than mean value of PBAC score in combined oral contraceptive pill group (127.18 \pm 16.7$)$. Significant difference in the PBAC score distribution of two groups was seen in the study $(\mathrm{p}<0.05)$. It is shown in Figure 2.

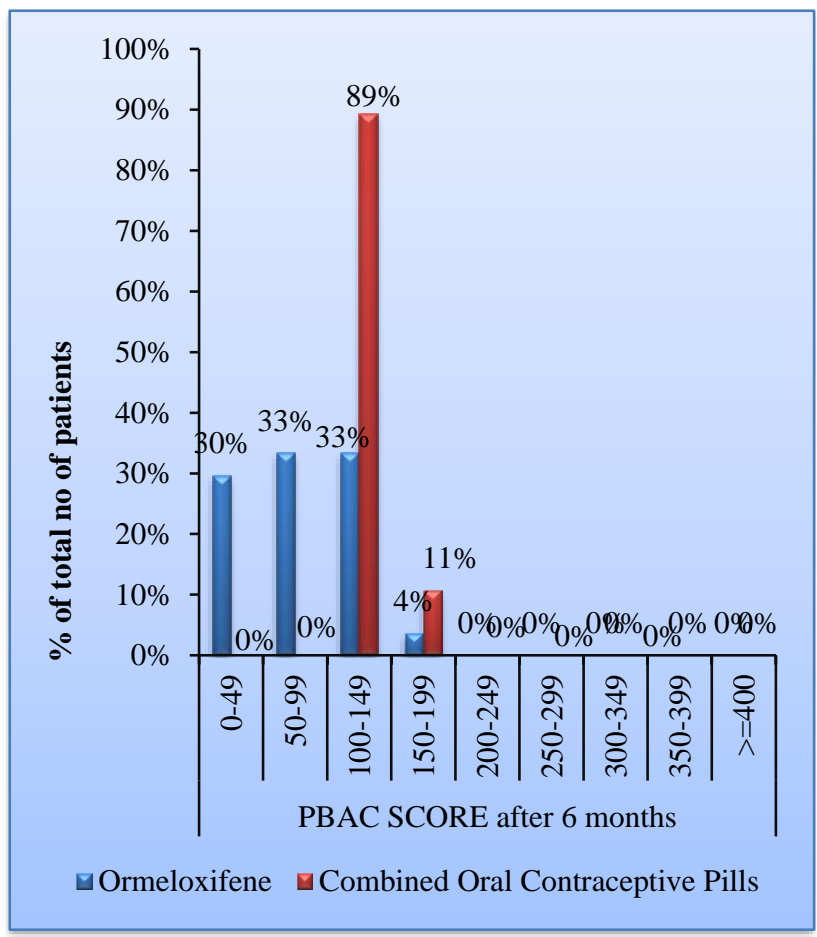

Figure 2: Comparison of PBAC score after 6 months in both groups.

The mean values of hemoglobin after 6 months of treatment in ormeloxifene group was $10.34 \pm 1.06 \mathrm{gm}$ which was significantly higher than mean value of hemoglobin in combined oral contraceptive pill group $(9.56 \pm 0.65 \mathrm{gm}) \quad(\mathrm{p}<0.05)$. Significant difference in the hemoglobin levels distribution of two groups was seen in the study $(\mathrm{p}<0.05)$. It is shown in Figure 3.

Majority of patients in both the groups had no side effects and incidence of side effects was comparable $(p>0.05)$. Distribution of type of side effects was significantly different between both the groups $(\mathrm{p}<0.05)$ In Ormeloxifene group, 7 patients had Amenorrhea and 1 patient had headache whereas in combined oral contraceptive pill group no patient had amenorrhea or 
headache. Majority of patients in combined oral contraceptive pill group had nausea and vomiting followed by weight gain. It is shown in Figure 4.

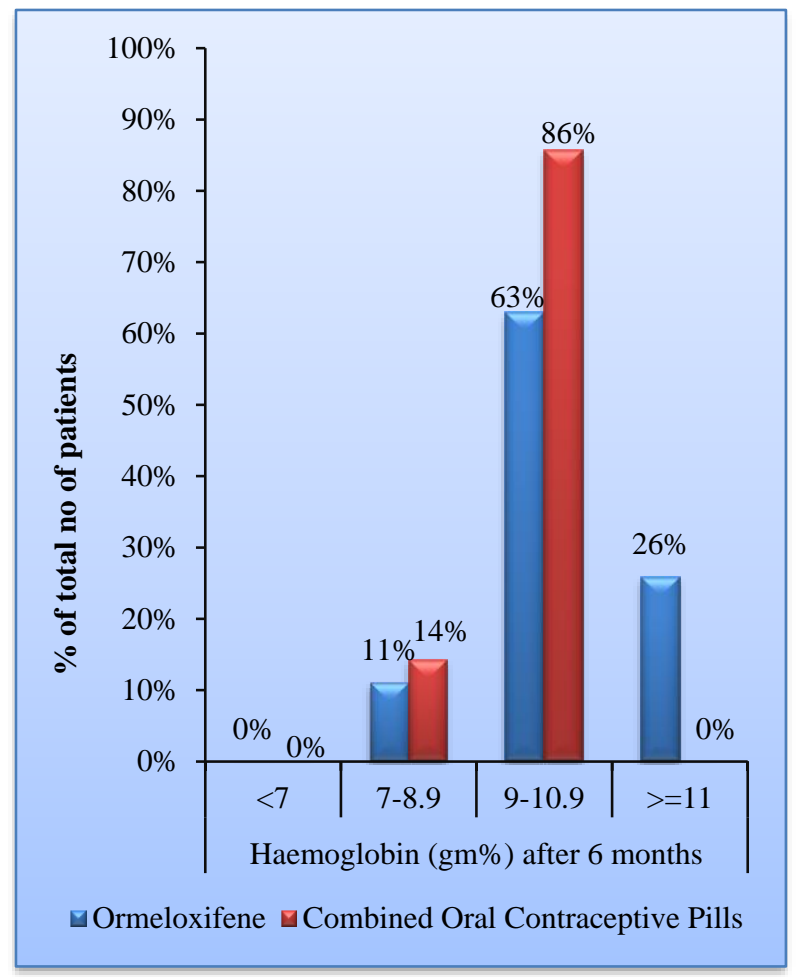

Figure 3: Comparison of $\mathrm{Hb}$ levels after 6 months in both groups.

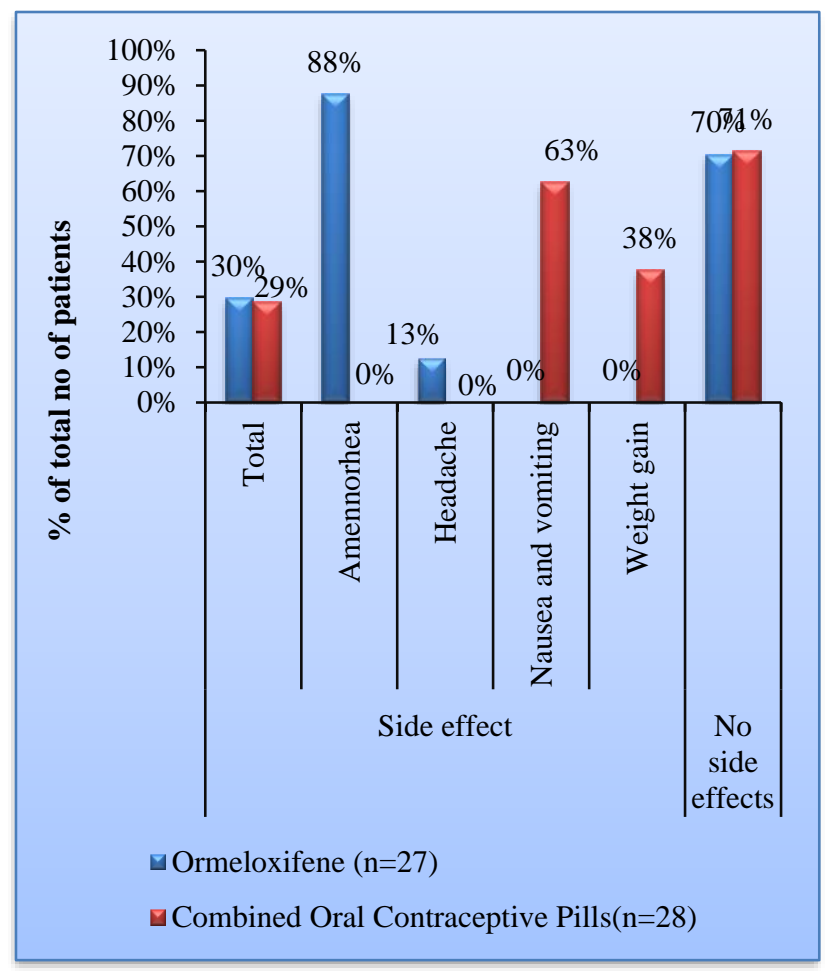

Figure 4: Comparison of side effects between both groups.

\section{DISCUSSION}

The traditional surgical treatment for menorrhagia is hysterectomy, which even though, offers an effective cure, involves major surgery with significant postoperative morbidity. Another alternative is endometrial ablation techniques with considerably reduced postoperative morbidity. They may be unsuitable for women wishing to retain their menstrual or reproductive function and require technical skills not available routinely. For women, who have not completed their family or who are unfit or unwilling to for surgery, or those keen to maintain their menstrual/reproductive function, medical treatment is only feasible option. Ormeloxifene (centchroman), a third generation selective estrogen receptor modulator (SERM) selectively has both estrogen agonist and antagonist in a ratio of 1:4. ${ }^{12}$ It regularizes the expression of estrogen receptors on endometrium normalizing the bleeding from uterine cavity; hence the drug was tried in patients of DUB by Kriplani et al, in their pilot study which demonstrated $99.7 \%$ reduction in mean blood loss. ${ }^{13}$

It is always hard to quantify mean blood loss objectively and is usually defined subjectively in clinical practice. We opted to use PBAC chart as used by Higham et al. ${ }^{14}$ It is a simpler and faster method, not requiring preservation of sanitary products and avoids costly chemical assay.

The ultimate goal of medical management of dysfunctional uterine bleeding is to resume the natural cycle of orderly endometrial growth and shedding. The selection of the treatment must be keeping in mind several factors like presence of anovulatory/ovulatory cycles and the need for contraception. Also, patient's inclination, the desire to avoid hormonal therapy and contraindication to drugs play a major role. ${ }^{9}$

The patients in this study comprised of patients in perimenopausal age group presenting with DUB. There was symptomatic improvement both group of drugs though the extent or degree of improvement varied in both the groups. In the present study, the reduction in menstrual blood loss (as assessed by fall in PBAC score), rise in hemoglobin concentration and decrease in endometrial thickness were significantly more with ormeloxifene than COCP after 6 months of therapy. The results were significant even after 3 months of therapy.

In a similar study, Neha et al used similar dose of ormeloxifene which was compared with norethisterone of $5 \mathrm{mg}$ twice daily for 21 days for 6 months. ${ }^{11}$ They too found ormeloxifene to be superior to norethisterone in reducing menstrual blood loss. The reduction in mean PBAC score was significant in both groups but was more with ormeloxifene (216 to 88 ) than norethisterone (262 to 162). The rise in hemoglobin concentration and fall in endometrial thickness were also significantly more with ormeloxifene than norethisterone (7.52 gm\% to $9.2 \mathrm{gm} \%$ 
vs. $7.48 \mathrm{gm} \%$ to $8.4 \mathrm{gm} \%, \mathrm{p}<0.05$, and $12.12 \mathrm{~mm}$ to 9.46 $\mathrm{mm}$ vs. 12.05 to $10.7 \mathrm{~mm}, \mathrm{p}<0.05$, respectively).

Shravage et al compared ormeloxifene to another progesterone, medroxyprogesterone acetate. ${ }^{15}$ They found $85.7 \%$ reduction in menstrual blood loss with ormeloxifene as compared to $54.76 \%$ with medroxyprogesterone acetate. The reduction in mean endometrial thickness was more with ormeloxifene; however, this difference was not statistically significant, maybe because of shorter period of observation of 3 months.

Shazia et al found significant reduction in median PBAC score from 322 to 54 after six months of treatment. ${ }^{16}$ The mean hemoglobin concentration increased significantly from 8.1 to $9.4 \mathrm{gm} / \mathrm{dl}$ with a rise of $1.3 \mathrm{gm} / \mathrm{dl}(\mathrm{p}<0.05)$. The mean pre-treatment endometrial thickness was $11 \mathrm{~mm}$ and it decreased significantly to $8.4 \mathrm{~mm}$ after 6 months of treatment with ormeloxifene $(\mathrm{p}<0.05)$.

Khare et al in their study concluded that ormeloxifene is a better drug in reducing the amount of bleeding with $81.67 \%$ patients showing marked improvement in PBAC score compared to COCP group patients, in which only $35 \%$ patients had shown marked improvement. ${ }^{17}$

In our study, $23.3 \%$ (7 women) women complained of amenorrhea as their chief presenting complaints which are comparable with other studies. However, with proper counselling, the women found it a desirable symptom at this age. No symptoms of nausea and vomiting and weight gain were encountered in ormeloxifene group while in combined oral contraceptive pill group, $63 \%$ had nausea and vomiting followed by weight gain in $38 \%$ patients. Neha et al, in their study found $8 \%$ cases receiving ormeloxifene had amenorrhea, $8 \%$ had hypomenorrhea and $4 \%$ developed nausea, vomiting and headache. ${ }^{5}$ Four percent cases receiving norethisterone had breakthrough bleeding and $14 \%$ cases had spotting. In Shazia et al, the most common side effect reported was amenorrhoea $(16 \%) .^{16}$

\section{Strengths}

It is a randomized control trial. So, both the groups were comparable in their basic characteristics. There was no difference in the quality of care given to Ormeloxifene group and COCP group. Both the groups were followed up regularly. This ruled out any kind of treatment deficit and at the same time provided the opportunity of early detection of any side effects. Compliance of the participants was good as all women belonged to severely symptomatic group. So, all of them were highly motivated for the follow-ups given to them.

Limitations of the study are that being a hospital-based study; the results cannot be extrapolated to general population. The sample size is also small in each group to extrapolate results for larger population and because of smaller sample size and study period, the issues regarding long term effects of the drug like changes in biochemical parameters (liver function test or lipid profile) cannot be extrapolated. Long term follows up of patients is required.

\section{CONCLUSION}

It can be concluded that both ormeloxifene and COCP significantly reduce blood loss in patients of perimenopausal DUB evidenced by decrease of PBAC score, rise in hemoglobin levels and decrease in CET levels. However, ormeloxifene was found to be superior to COCP in reducing the menstrual blood loss. Ormeloxifene was also tolerated better compared to COCP with fewer side effects experienced by patients. Amenorrhea with the use of ormeloxifene was a desirable side effect in the perimenopausal age group. So Ormeloxifene could be the drug of choice in patients of DUB in the perimenopausal age group.

\section{Funding: No funding sources}

Conflict of interest: None declared

Ethical approval: The study was approved by the Institutional Ethics Committee

\section{REFERENCES}

1. Bravender T, Emans S. Menstrual Disorders. Dysfunctional Uterine Bleeding. Pediatr Clin North Am. 1999;3(46):545-53.

2. Dadich SA, Soni M, Jain R. Role of ormeloxifene in medical management of dysfunctional uterine bleeding. Asian J Obs Gynae Pract. 2012;6:28-31.

3. Singh HO, Singh A, Dhole TN, Nain S. Biochemistry and Physiology. Open Access Effect of Ormeloxifene for Management of Dysfunctional Uterine Bleeding. Biochem Physiol. 2015;4(3):4-6.

4. Practice C. Efficacy of a Selective Estrogen Receptor Modulator: 'Ormeloxifene' in Management of Dysfunctional Uterine Bleeding. Biochem Physiol. 2010;2:207-11.

5. Grover S, Chhabra A, Bindu S. A Study of Ormeloxifene in Case of Dysfunctional Uterine Bleeding. Int J Med Dent Sci. 2013;2(2):162-9.

6. KJ J. A comparative study on the effectiveness of ormeloxifene versus norethisterone in the management of perimenopausal dysfunctional uterine bleeding. IAIM. 2015;88.

7. Komaram R, Palla J, Swamy Chintada G. A study of efficacy of ormeloxifene in the pharmacological management of dysfunctional uterine bleeding. J Clin Diagnostic Res. 2013.

8. Goldstein SR, Nanavati N. Selective Oestrogen Receptor Modulator Levormeloxifene in the treatment of osteoporosis. Am J Obstet Gynaecol. 2002;187(3):521.

9. Cardoso PM. A Comparative Study of the Efficacy of Ormeloxifene and Norethisterone in Perimenopausal Dysfunctional Uterine Bleeding and Perimenopausal Symptoms. J Dental Med Sci. 2016;15(1):57-62. 
10. Agarwal NU, Kriplani A. Medical management of dysfunctional uterine bleeding. Int J Gynaecol Obstet. 2001;7:199-201.

11. Agarwal N, Singh S, Singh S, Agarwal M, Manocha P. Comparative evaluation of the efficacy and safety of ormeloxifene and norethisterone in dysfunctional uterine bleeding. Int J Reprod Contraception, Obstet Gynecol. 2013;2(2):194.

12. Alexandersen P, Riis BJ, Stakkestad JA, Delmas PD. Efficacy of Levormeloxifene in the Prevention of Postmenopausal Bone Loss and on the Lipid, Profile Compared to Low Dose Hormone Replacement Therapy. J Clin Endocrinol Metab. 2001;86(2):75560 .

13. Kriplani A, Kulshrestha V, Agarwal N. Efficacy and safety of ormeloxifene in management of menorrhagia: A pilot study. J Obstet Gynaecol Res. 2009;35(4):746-52.

14. Higham JM, O’Brien PM, Shaw RW. Assessment of menstrual blood loss using a pictorial chart. $\mathrm{Br} \mathrm{J}$ Obstet Gynaecol. 1990;97(8):734-9.
15. Shravage J, Mekhala D, Bellad MB, Ganachari MS, Dhumale HA. Ormeloxifene versus medroxyprogesterone acetate (MPA) in the treatment of dysfunctional uterine bleeding: A double-blind randomized controlled trial. J SAFOG. 2011.

16. Khan SA, Manzoor M, Abdullah A, Banoo A. Efficacy and Safety of Ormeloxifene in the Management of Dysfunction Uterine Bleeding. J Dent Med Sci. 2014;13(6):39-42.

17. Khare V, Ghosh G, Patil P, Nagar N. Ormeloxifen HCL (SERM), Oral Contraceptive Pills, DUB. Ormeloxifen HCL VS Comb oral Contracept PILL Treat DUB. 2014;3084.

Cite this article as: Shah M, Parmar C, Gor R. Comparative study of ormeloxifene and low dose oral contraceptive pill for the treatment of dysfunctional uterine bleeding in peri-menopausal age group. Int J Reprod Contracept Obstet Gynecol 2021;10:3112-8. 